\title{
Comparison of Spatial Firing Characteristics of Units in Dorsal and Ventral Hippocampus of the Rat
}

\author{
Min W. Jung, ${ }^{1}$ Sidney I. Wiener, ${ }^{2}$ and Bruce L. McNaughton' \\ 'Department of Psychology and Arizona Research Laboratories, Division of Neural Systems, Memory and Aging, \\ University of Arizona, Tucson, Arizona 85724 and ${ }^{2}$ Centre National de la Recherche Scientifique, Collège de France \\ Laboratoire de Physiologie de la Perception et del'Action, 75270 Paris Cedex 06, France
}

\begin{abstract}
The septal and temporal poles of the hippocampus differ markedly in their anatomical and neurochemical organization. Although it is well established that the internal representation of space is a fundamental function of hippocampal neurons, most of what is known about spatial coding in the hippocampus of freely moving animals has come from recordings from the dorsal one-third (largely for technical convenience). The present study therefore compared the spatial selectivity of CA1 neurons in the dorsal and ventral hippocampi of rats during performance of a food reinforced, random search task in a square chamber containing simple visual landmarks. Neural activity was recorded in the dorsal and ventral hippocampi of opposite hemispheres in the same rats, in many cases simultaneously. As in dorsal hippocampus, ventral CA1 units could be classified as "complex spike" (pyramidal) cells or "theta" interneurons. Both dorsal and ventral theta cells fired at relatively high rates and with low spatial selectivity in the apparatus. Of the population of complex spike cells in the ventral hippocampus, a significantly smaller number had "place fields" than in the dorsal hippocampus, and the average spatial selectivity was of significantly lower resolution than that found among dorsal hippocampal complex spike cells. Thus, a septotemporal difference of spatial selectivity was found in the CA1 field of the rat hippocampus, complementing many other anatomical and neuropharmacological studies. A number of possible functional interpretations can be suggested from these results, including a computational advantage of representing space at different scales or a preeminence of essentially nonspatial information processing in the ventral hippocampus.
\end{abstract}

[Key words: temporal hippocampus, place, memory, CA1, unit, spatial]

The hippocampus is believed to be involved in spatial learning and memory both in rats and primates. One line of critical supporting evidence is the existence of "place cells." The discharge selectivity of hippocampal neurons in freely moving rats

Received Mar. 4, 1994; revised June 13, 1994; accepted June 16, 1994

This work was supported by National Institute of Health grant (NS20331) to B.L.M. and Human Frontiers Scientific Program grant to B.L.M. and S.I.W. We thank Kevin Moore and Sheila Kipen for technical assistance, William Skaggs for help with analysis, and James Knierim for helpful comments on the manuscript.

Correspondence should be addressed to Dr. M. W. Jung, Life Sciences North Building, Room 384, University of Arizona, Tucson, AZ 85724.

Copyright (C) 1994 Society for Neuroscience $0270-6474 / 94 / 147347-10 \$ 05.00 / 0$ shows a remarkable correlation with the position of the animal (O'Keefe and Dostrovsky, 1971; O'Keefe, 1976; Olton et al., 1978; McNaughton et al., 1983a; Muller et al., 1987; Jung and McNaughton, 1993). These results, however, have come from recordings restricted to the dorsalmost quarter of the hippocampus, primarily hecause its superficial position facilitates electrode placement; yet, many other types of studies have shown wide variations along the septotemporal axis of the hippocampus with regard to properties that are likely to have functional significance. For example, variations occur in the cortical origins of afferent projections (Ruth et al., 1982, 1988; Witter and Groenewegen, 1984; Van Groen and Lopes Da Silva, 1985, 1986; Van Groen et al., 1986; Witter et al., 1988, 1989b), sites of output terminations in the cortex (Siegel and Tassoni, 1971; Swanson and Cowan, 1977; Swanson, 1981; Van Groen and Lopes Da Silva, 1986; Van Groen et al., 1986; Van Groen and Wyss, 1990; Wyss and Van Groen, 1992), commissural and intrinsic connections (Fricke and Cowan, 1978; Swanson et al., 1978; Laurberg, 1979; Van Groen and Wyss, 1990; Cavazos et al., 1992; Li ct al., 1994), and connections with subcortical structures (for review, see Witter, 1986, 1993; Swanson et al., 1987; Witter et al., 1989a; Lopes Da Silva et al., 1990). Of particular interest are the facts that only the ventral CA1 area projects to the medial prefrontal cortex (Swanson, 1981; Ferino et al., 1987; Jay et al., 1989; Jay and Witter, 1991) and only the ventral hippocampus is connected to the amygdala (Krettek and Price, 1977; Russchen, 1982; Van Groen and Wyss, 1990), while the dorsal hippocampus dominates the projection to the perirhinal cortex (Swanson and Cowan, 1977; Van Groen and Wyss, 1990). In addition, there exist a host of differences in neurochemistry (see below), and the proportions of morphologically identified cell types vary as well (Gaarskjaer, 1978; Seress and Pokorny, 1981).

Physiological properties also vary along the septotemporal axis. The septal and the temporal hippocampi exhibit differences with regard to seizure induction and kindling of epileptic foci (Elul, 1964; Racine et al., 1977; Bragdon et al., 1986; Lee et al., 1990; Williamson et al., 1991; Cavazos et al., 1992), eventrelated potentials (Brazier, 1970), vulnerability to ischemia (Ashton et al., 1989), and evoked field potential responses (Gilbert et al., 1985). Also, electrical stimulation, pharmacological manipulations, or lesions selective to the dorsal and the ventral hippocampus provide dissociable bchavioral changes (Nadel, 1968; Siegel and Flynn, 1968; Stevens and Cowey, 1973; Lanier and Isaacson, 1975; Koreli, 1977; Blozovski, 1979; Chiba et al., 1992; Moser et al., 1993), although interpretations of the stimulation and lesion data are obscured in some cases by possible 
unintended effects on fimbria-fornix fibers, since fibers from the entire hippocampus accumulate in the dorsal portion.

The existing data therefore point to a functional differentiation along the septotemporal axis of the hippocampus. The present study addressed the possibility of septotemporal variations in the spatial selectivity of unit firing, which is among the clearest and most remarkable of behavioral correlates of hippocampal neurons. Specifically, this study was designed to answer the following questions. (1) Can units in the ventral CAl area be classified as "complex spike" and "theta" cells (Ranck, 1973) as in the dorsal counterpart, and are their firing rates and temporal discharge characteristics similar to cells of dorsal hippocampus? (2) Is place-selective firing present in cells of the ventral hippocampus in the same proportions as in the dorsal, and are the spatial specificity and information content of ventral cells comparable to dorsal ones?

\section{Materials and Methods}

Behavioral tasks. Seven male Fischer-344 rats aged 9 months were extensively handled and then food deprived to approximately $80-90 \%$ of their ad libitum body weight. Lights were on in the colony room between 10 P.M. and 10 A.M., and experiments were conducted between 7 A.M. and 5 P.M. The rats were trained in a square chamber $(68 \times$ $68 \mathrm{~cm}, 51 \mathrm{~cm}$ height) placed on an elevated table covered with fresh paper. The chamber walls were dark gray in color and one was covered with a white card (Muller et al., 1987). The recording room was soundattenuating and moderately illuminated by four ceiling lamps mounted symmetrically with respect to the recording chamber. In the light of recent evidence that initial disorientation can cause place cells to exhibit rotational instability from trial to trial (Jung and McNaughton, 1993; Knierim et al., 1993), the rats were introduced into the recording room without intentionally disorienting them. The behavioral task was to seek small (10-20 mg) chocolate pellets (Muller et al., 1987) that were distributed by an automatic dispenser installed on the ceiling. Two to four pellets were released every $8-13 \mathrm{sec}$. The rats learned to retrieve the food and visit all parts of the floor typically within several days of training. The rat was alone in the experimental room during training and recordings.

Electrode implantation. Surgeries were conducted according to NIH guidelines. The rats were deeply anesthetized with Nembutal $(40 \mathrm{mg} /$ $\mathrm{kg}$ ) and two separate microelectrode drivers (McNaughton et al., 1989) were installed on opposite sides of the skull, one aimed at the dorsal hippocampus (3.3-3.8 $\mathrm{mm}$ posterior and 1.7-2.0 lateral to bregma) and the other at the ventral hippocampus $(5.8-6.3 \mathrm{~mm}$ posterior and 5.5 5.8 lateral to bregma). Of the seven animals, five right and two left hemispheres were implanted with ventral electrodes and the corresponding opposite hemispheres received dorsal ones. The electrodes ("tetrode"; McNaughton et al., 1983b; Recce and O'Keefe, 1989; Wilson and McNaughton, 1993) consisted of bundles of four polyimide-insulated nichrome wires (H. P. Reid Co., Palm Coast, FL) twisted together and gently heated to fuse the insulation without short-circuiting the wires. The final overall diameter was $40 \mu \mathrm{m}$. Two such tetrodes were mounted together in a guide cannula (30 gauge). In most cases the tetrodes destined for the ventral hippocampus were reinforced with Epoxylite. The electrode tips were cut and gold-plated to reduce their impedance to $0.2-0.7 \mathrm{M} \Omega$ measured at $1 \mathrm{kHz}$. Each pair of tetrodes was glued together with cyanoacrylate cement, allowing a longitudinal spacing of $0.5 \mathrm{~mm}$ between the tips of the adjacent tetrodes. This spacing permitted one of the tetrode wires to serve as a reference electrode outside of the cell layer for differential recordings. Seven anchor screws were implanted on the skull, one of which was used as a ground lead. The entire implant was encased in dental acrylic.

Unit recording. The baseline recordings and electrode advancements were made in the room adjacent to the testing room. The hippocampal pyramidal cell layer was identified by the depth of the electrode and the characteristic $200 \mathrm{~Hz}$ "ripple" (Sharp-wave) activity (O'Keefe and $\mathrm{Na}$ del, 1978; Buzsáki et al., 1992). When well-isolated and stable units were found, baseline unit activities were recorded for about $30 \mathrm{~min}$ while the animal was sitting quietly on a pedestal. The animal was in slow wave sleep during most of this period. In this way, cells that might be silent in the awake animal (Thompson and Best, 1989) were sampled and the proportion of detectable cells with place fields could be determined. Following baseline recording, the rat was allowed to run in the arena for $30 \mathrm{~min}$.

Unit signals were recorded via an FET source-follower headstage mounted on the animal's head. Output signals from the headstage were filtered between 0.6 and $6 \mathrm{kHz}$, digitized at $32 \mathrm{kHz}$, and stored on a 80486 personal computer for future off-line analysis. The data were transferred to a SUN 4 workstation and units were isolated by projecting the 4-channel relative amplitude data two-dimensionally, and applying boundaries to each subjectively apparent, unit cluster (McNaughton et al., 1983b, 1989). Care was taken to apply the same criteria to all cells in the population. An example of a tetrode recording is shown in Figure 1 .

Two sets of infrared light-emitting diodes were mounted on the recording headstage $12 \mathrm{~cm}$ apart, parallel to the longitudinal body axis. The animal's location and head direction were monitored by tracking the relative locations of the large front diode array, containing four or five diodes, and the small back diode array, containing onc or two diodes, at 20 frames $/ \mathrm{sec}$.

Analysis. A firing rate map was constructed for the initial analysis. The $168 \times 168 \mathrm{~cm}$ square containing the apparatus was divided into $64 \times 64$ bins, and the firing rate (total number of spikes divided by total occupancy time) for each bin was calculated. "Adaptive binning" (Skaggs and McNaughton, unpublished observations) was employed in the present study to optimize the trade-off between sampling error and resolution. Sampling radius of a bin was increased starting from 0 until the following condition was met:

$$
d \geqq \alpha / n \sqrt{s},
$$

where $d$ is the sampling radius, $\alpha$ is the sampling radius scale factor, which was set at 1000 for the present analysis, $n$ is the number of occupancy samples lying within the circle, and $s$ is the total number of spikes contained in those occupancy samples. The chosen radius is a trade-off value between "sampling" error, which is the error introduced by a small number of samples, and "blurring" error, which is the error introduced by sampling from locations having different actual firing rates from the location in question. The algorithm can be viewed as a process of obtaining the minimal sampling radius required to register enough occupancy data for statistical reliability of the rate measure.

A "place field" was defined according to the criteria of Muller et al. (1987): a group of adjoining bins (sharing at least one side) with the average firing rate of each bin exceeding a specified threshold. Different investigators have used different definitions for the minimal number of bins and the threshold (e.g., Muller et al., 1987; Thompson and Best, 1990). For this study the minimal number of adjacent bins was set at 4 , and the threshold was set at a constant rate of $1 \mathrm{~Hz}$. A constant value was used, rather than a given number of standard deviations above the mean, because it gives more insight into the contributions of individual cells to the population activity pattern. The value of $1 \mathrm{~Hz}$ was chosen because, in many previous studies, complex spike cells in CA1 were very rarely found to fire at higher rates in all parts of an apparatus (e.g., Wilson and McNaughton, 1993). The size of a place field was defined as the number of bins in a place field, and the number of place fields for a given neuron was taken as the number of noncontiguous individual fields.

The information per spike and sparsity (Skaggs et al., 1993; Skaggs and McNaughton, unpublished observations) were calculated as measures of the spatial selectivity of unit firing in the following way:

$$
\begin{aligned}
\text { Information per spike } & =\sum_{i}\left(\frac{\lambda_{i}}{\lambda}\right) \cdot \log _{2}\left(\frac{\lambda_{i}}{\lambda}\right) \cdot p_{i}, \\
\text { Sparsity } & =\frac{\langle\lambda\rangle^{2}}{\left\langle\lambda^{2}\right\rangle}=\frac{\left(\Sigma p_{i} \lambda_{i}\right)^{2}}{\left(\Sigma p_{i} \lambda_{i}^{2}\right)},
\end{aligned}
$$

in which $\lambda_{i}$ is the mean firing rate of a unit in the $i$ th bin, $\lambda$ is the overall mean firing rate, $p_{i}$ is the probability of the animal being in the $i$ th bin (occupancy time in the $i$ th bin/total recording time), and angle brackets $(\langle\rangle)$ denote the expected value over locations. To minimize the dependence of the values on the rat's behavior, $p_{i}$ in the formulas is made into a uniform probability distribution over all the bins that are visited. That is, for every $i, p_{i}=1 / n$, where $n$ is the total number of bins visited. Information per spike is a measure of how much information about spatial location is conveyed by a single impulse of a given cell. Sparsity is a measure of how diffuse the unit firing is in the spatial domain. For illustration, if a unit fires equally all over the apparatus, the information 


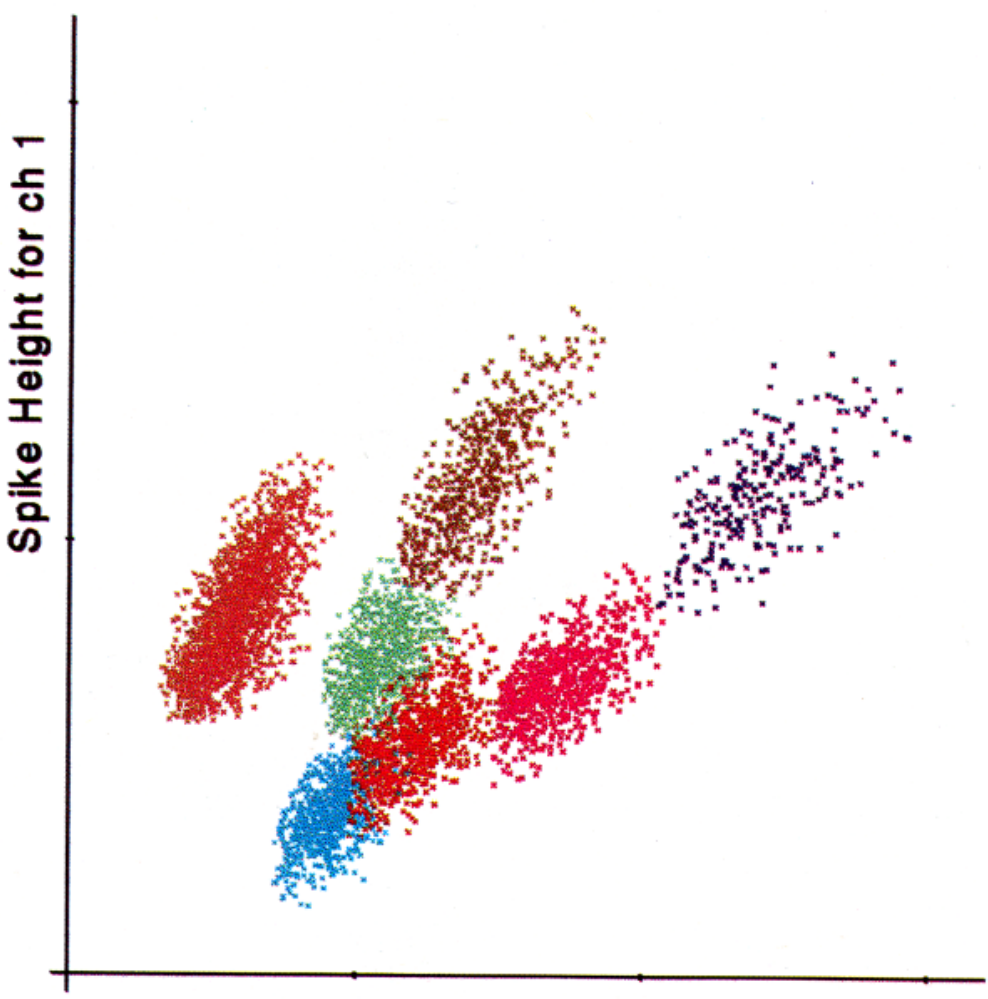

Spike Height for ch 2

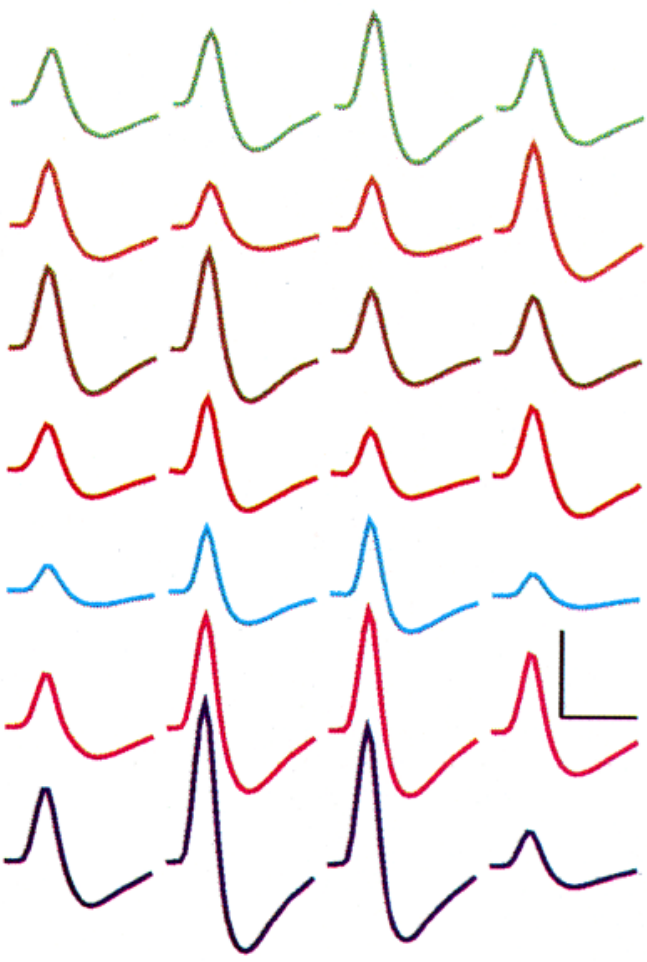

ch 1 ch 2 ch $3 \quad$ ch 4

Figure 1. An example of multiple single-unit recording with a tetrode. This recording was made for 30 min in the ventral CA1 cell body layer while the rat was in slow wave sleep. Each point in the scatterplot represents a signal that exceeded the experimenter-defined threshold. The $x$ and $y$-axes represent peak amplitudes of spike signals recorded by channels 2 and 1 , respectively, of the four tetrode channels. As shown, individual units tend to form clusters. In this example, all of the units were complex spike cells. Average spike waveforms recorded by each channel ( $c h$ 1ch 4) are also shown. One to 14 units were simultaneously recorded through single tetrodes in the present study. The figure shows an example with the median number of units (seven). Calibration: $0.5 \mathrm{msec}, 0.2 \mathrm{mV}$.

per spike is 0 and sparsity is 1 ; if a unit fires evenly over one half of the apparatus but never fires in the other half, the information per spike is 1 bit and sparsity is 0.5 .

Empirically, the sparsity and information per spike values are usually reproducible to $\pm 20 \%$ as long as there are at least 50 spikes in the sample, and the animal's behavior is good (i.e., the animal visits each part of the apparatus at least five times and does not spend long periods sitting still) (Skaggs and McNaughton, unpublished observations). Therefore, only the units that emitted more than 50 spikes were included for analyses. The rejected cells were considered to have no place field.

Spatial specificity is not the only important measure of the "quality" of a spatial representation. It is possible for a distributed representation, with each cell firing robustly over a broad region, to be more informative than a sparse representation. A direct measure of the amount of spatial information conveyed by the firing rate of a single cell is given by a formula very similar to the formula for information per spike: the information rate of the spike train equals the information per spike multiplied by the mean firing rate of the cell (Skaggs et al., 1993). Unlike the information per spike formula, this measure remains valid even when the number of spikes in the sample is very small; because of the multiplication by the mean firing rate, it yields a result close to zero in this case. Therefore, all recorded cells were included for analysis for this measure.

All statistical analyses compared the populations of dorsal and ventral complex spike cells. Due to the small sample size, no statistical analysis was applied for dorsal or ventral theta cells (see Results for unit classification). The $\chi^{2}$ test was used to compare the proportion of cells with place fields. Mann-Whitney nonparametric tests were used for all other comparisons. The results are expressed as mean \pm SEM.

Histology. When recordings were terminated, an electrolytic current $(50 \mu \mathrm{A}$, cathodal, $5 \mathrm{sec})$ was applied through one of the recording electrodes. On the next day the animal was deeply anesthetized and perfused with buffered $10 \%$ formal-saline while the electrode remained in situ.
The electrodes were not removed from the brain for $24 \mathrm{hr}$, to aid the reconstruction of electrode tracks. The brain was then removed, left in formal saline for 3-7 d, and then transferred to a $10 \%$ formal-saline/ $30 \%$ sucrose solution for 3-5 d until it sank to the bottom. Sagittal sections $40 \mu \mathrm{m}$ thick were cut on a sliding microtome and stained with cresyl violet.

\section{Results}

Histology. Under a light microscope, all of the tracks and lesion sites were unequivocally identified for each rat. All the recording sites were verified to be in the CAl cell body layer for both dorsal and ventral hippocampal penetrations (Fig. 2). The recording sites for the dorsal and ventral hippocampus corresponded to about $20 \%$ and $65 \%$, respectively, of the distance along the septotemporal axis.

Unit classification. A total of 83 and 134 well-isolated units were recorded from the dorsal and ventral hippocampus, respectively, from seven rats. Dorsal units were recorded from six hemispheres and ventral units were recorded from six hemispheres. Both dorsal and ventral units were classified as "complex spike" and "theta" cells (Ranck, 1973) based on spike discharge characteristics. The units that fired in complex bursts were classified as complex spike (CS) cells, and the units that exclusively fired in single isolated spikes were classified as theta cells (Fig. 3A). Most theta cells had short-duration spike waveforms, fired at relatively high rates (Fig. $3 B$ ), and, during running, increased their firing rates and were distinctly modulated at the theta $(7-8 \mathrm{~Hz})$ frequency (Fig. $3 A)$. In contrast, most CS 
Figure 2. Electrode placements. Each circle indicates a recording site in the dorsal $(A)$ or the ventral $(B-D)$ CA 1 cell body layer in the sagittal plane. Due to variations in gross morphology, the ventral recording sites are indicated at three different levels in the mediolateral dimension, with $B$ the most medial and $D$ the most lateral.
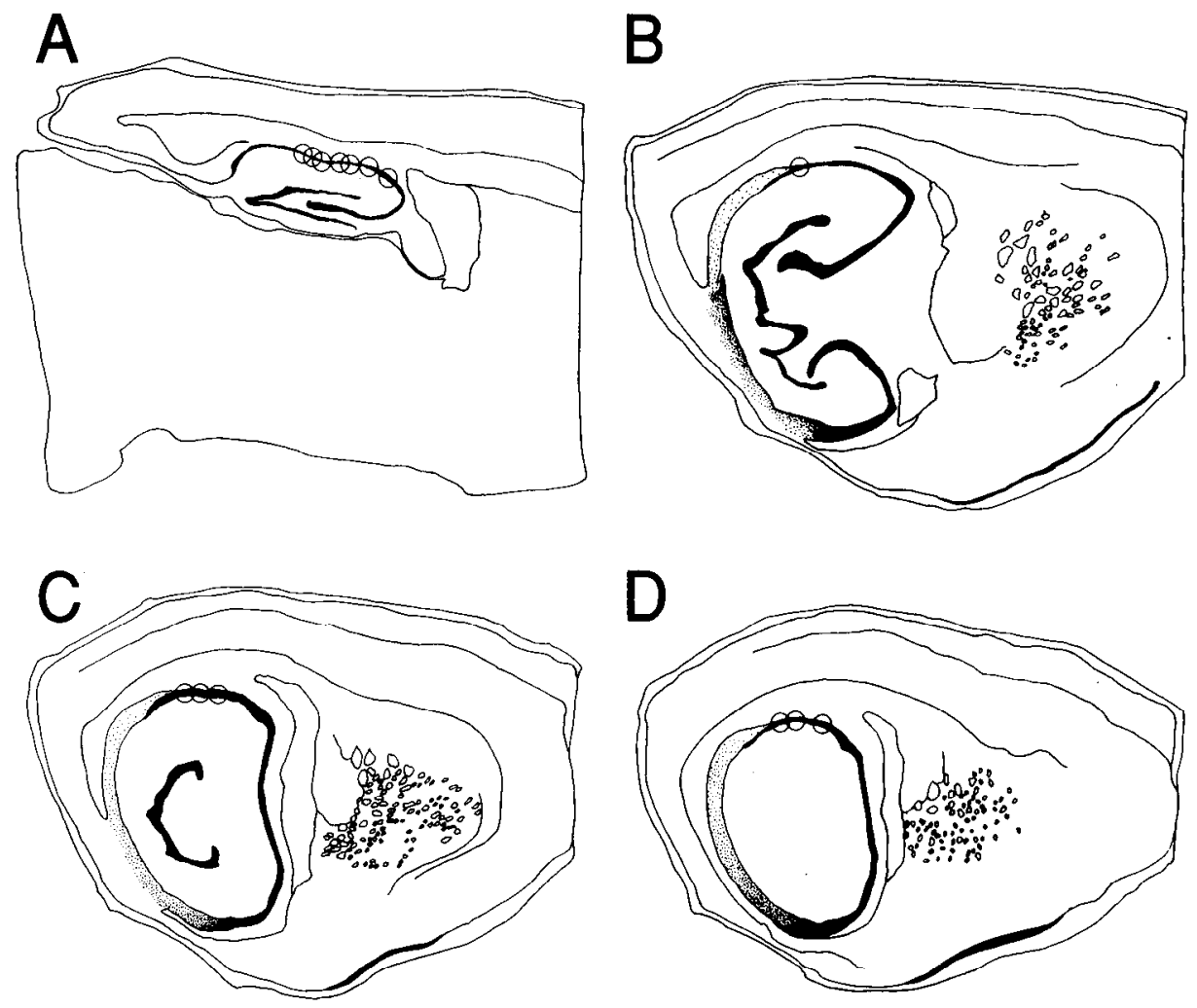

cells had longer-duration waveforms, discharged at low average rates (Fig. $3 B$ ), and were most active when the animal was in slow wave sleep. These characteristics of CS and theta cells are consistent with previous reports (Ranck, 1973; Barnes et al., 1990). Three of 83 dorsal units and 5 of 134 ventral units were classified as theta cells. The rest of the recorded units were CS cells.

Characteristics of unit discharge during baseline. In general, ventral CS cells had similar characteristics to dorsal CS cells during the baseline period (see above), when the animals were typically sleeping on a pedestal. Baseline firing rates were 0.54 \pm 0.13 and $0.33 \pm 0.05 \mathrm{~Hz}$ for dorsal and ventral CS cells, respectively (Table 1). Some units fired at high rates during the baseline period (Fig. 3). This is probably due to the fact that animals were sometimes vigilant during the baseline period and some units had place fields on the pedestal. There was a small but significant difference in the spike duration (defined as the interval between maximum and minimum voltage of a filtered spike waveform; $Z=3.80, p<0.001)$. Ventral CS cells had slightly shorter $(302 \pm 5 \mu \mathrm{S})$ spike duration than dorsal CS cells $(328 \pm 7 \mu \mathrm{S})$. This small difference may be due to different electrical properties between dorsal and ventral electrodes; ventral electrodes were longer and strengthened with Epoxylite, which may have led to different capacitance values from dorsal electrodes. It is also possible that the apparent difference in spike duration night be due to the fact that the electrodes approached

Table 1. Average spike discharge parameters for each cell type

\begin{tabular}{lccccc} 
& \multicolumn{3}{l}{ CS cells } & & \multicolumn{2}{l}{ Theta cells } \\
\cline { 2 - 3 } \cline { 5 - 6 } & Dorsal & Ventral & & Dorsal & Ventral \\
\hline Number of units & 80 & 129 & 3 & 5 \\
Spike height $(\mu \mathrm{V})$ & $189 \pm 10$ & $191 \pm 10$ & $174 \pm 61$ & $130 \pm 5$ \\
Spike duration $(\mu \mathrm{S})$ & $328 \pm 7$ & $302 \pm 5^{*}$ & & $187 \pm 0$ & $218 \pm 17$ \\
Baseline firing rate $(\mathrm{Hz})$ & $0.54 \pm 0.13$ & $0.33 \pm 0.05$ & & $8.2 \pm 2.7$ & $7.9 \pm 1.1$ \\
Running firing rate $(\mathrm{Hz})$ & $0.29 \pm 0.05$ & $0.35 \pm 0.09^{*}$ & & $14.4 \pm 4.2$ & $16.1 \pm 2.9$ \\
Information per spike (bits) & $1.22 \pm 0.10$ & $0.48 \pm 0.04^{*}$ & & $0.02 \pm 0.00$ & $0.05 \pm 0.02$ \\
Sparsity & $0.32 \pm 0.02$ & $0.59 \pm 0.02^{*}$ & & $0.97 \pm 0.00$ & $0.94 \pm 0.02$ \\
Information rate (bits/sec) & $0.32 \pm 0.05$ & $0.13 \pm 0.03^{*}$ & & $0.32 \pm 0.13$ & $0.50 \pm 0.17$ \\
Number of units with place fields & $36(45 \%)$ & $22(18 \%)^{*}$ & & \\
Size of place fields (bins) & $67.0 \pm 7.5$ & $272.0 \pm 44.3^{*}$ & & \\
Average maximum firing rate & & & & \\
$\quad$ for place cells $(\mathrm{Hz})$ & $7.92 \pm 0.56$ & $9.82 \pm 1.63$ & &
\end{tabular}

Only the units that emitted 50 or more spikes are included for information per spike and sparsity measures. Data are expressed in mean \pm SEM. CS cells, complex spike cells.

* Significant difference between dorsal and ventral complex spike cells. 
the cells from different angles, with respect to their dendrites. This would alter the shape of the extracellular voltage transient. Ventral theta cclls also appeared to have similar characteristics to dorsal theta cells during the baseline period (see above). The average spike durations were $187 \pm 0$ and $218 \pm 17 \mu \mathrm{S}$, and the baseline firing rates were $8.2 \pm 2.7$ and $7.9 \pm 1.1 \mathrm{~Hz}$ for dorsal and ventral theta cells, respectively (Table 1).

Spatial firing patterns of complex spike cells. Both dorsal and ventral hippocampus had CS cells that preferentially fired as the rat occupied certain locations in the arena (place fields); however, they showed clearly different characteristics in two respects. Only $18 \%$ (22 of 129) of ventral hippocampal CS cells had place fields, whereas $45 \%$ (36 of 80 ) of the dorsal CS cells had place fields $\left(\chi^{2}=52.7, p<0.001\right)$. The rest of the cells were either silent or fired at low rates with little spatial bias. Second, ventral hippocampal CS cells, on the whole, had lower spatial specificity as measured by our two indices. The spatial information per spike measure of dorsal CS cells was more than twice that of ventral neurons $(1.22 \pm 0.10$ bits for dorsal and $0.48 \pm$ 0.04 bits for ventral, $Z=6.06, p<0.001)$. The sparsity measure of dorsal CS cells was about half of that of ventral CS cells $(0.32$ \pm 0.02 for dorsal and $0.59 \pm 0.02$ for ventral, $Z=6.02, p<$ $0.001)$. The average information rate measure was higher for the dorsal CS cells, too $(0.32 \pm 0.05$ for dorsal and $0.13 \pm 0.03$ for ventral, $Z=4.67, p<0.001)$. Also, place field size was much smaller for dorsal CS cells compared to ventral CS cclls $(67.0 \pm 7.5$ bins for dorsal and $272.0 \pm 44.3$ bins for ventral, $Z=3.2, p=0.001$; both place fields were entered into the analysis for cells with dual place fields) (Table 1). There was no significant difference between the distributions of dorsal and ventral place field centers in the arena $(p>0.05)$, indicating that place field location is not a source of the difference in spatial selectivity. If only those cells recorded simultaneously in the dorsal and ventral hippocampus ( $n=42$ for dorsal and $n=61$ for ventral CS cells from three rats) are considered, these differences still persist (information per spike: $Z=3.71, p<0.001$; sparsity: $Z=3.73, p<0.001$; information rate: $Z=3.46, p<$ 0.001 ; field size: $Z=2.09, p=0.037$ ). All the spatial firing maps for dorsal and ventral CS cells with place fields in the apparatus are shown in Figure 4. As illustrated, some ventral place fields were as large as $80 \%$ of the entire recording apparatus (i.e., sparsity is about 0.8 ), whereas others were as small as the typical dorsal place field. The distribution of information per spike and sparsity measures for all the units that entered the analysis (i.e., units with more than 50 spikes) is shown in Figure 5. The average maximum firing rate (i.e., the highest of the average firing rate of each bin) of dorsal place cells was not different from that of ventral place cells (7.92 \pm 0.56 and 9.82 $\pm 1.63 \mathrm{~Hz}$, respectively; $p>0.05$ ). Due to those ventral units that had large place fields, ventral CS cells had higher overall firing rates in the arena than dorsal CS cells $(0.29 \pm 0.05 \mathrm{~Hz}$ for dorsal and $0.35 \pm 0.05 \mathrm{~Hz}$ for ventral units, $Z=3.8, p<$ $0.001)$.

Most of the dorsal and ventral units had only one place field; however, 8 of 36 dorsal and 3 of 22 ventral units had two place fields (Fig. 4). For these cells, however, there remains the possibility that the recording was made up of more than one single unit.

Spatial firing pattern of theta cells. There were not enough cells for quantitative comparisons between dorsal and ventral theta cells ( $n=3$ and 5, respectively); however, upon direct visual examination, the spatial firing patterns of ventral theta
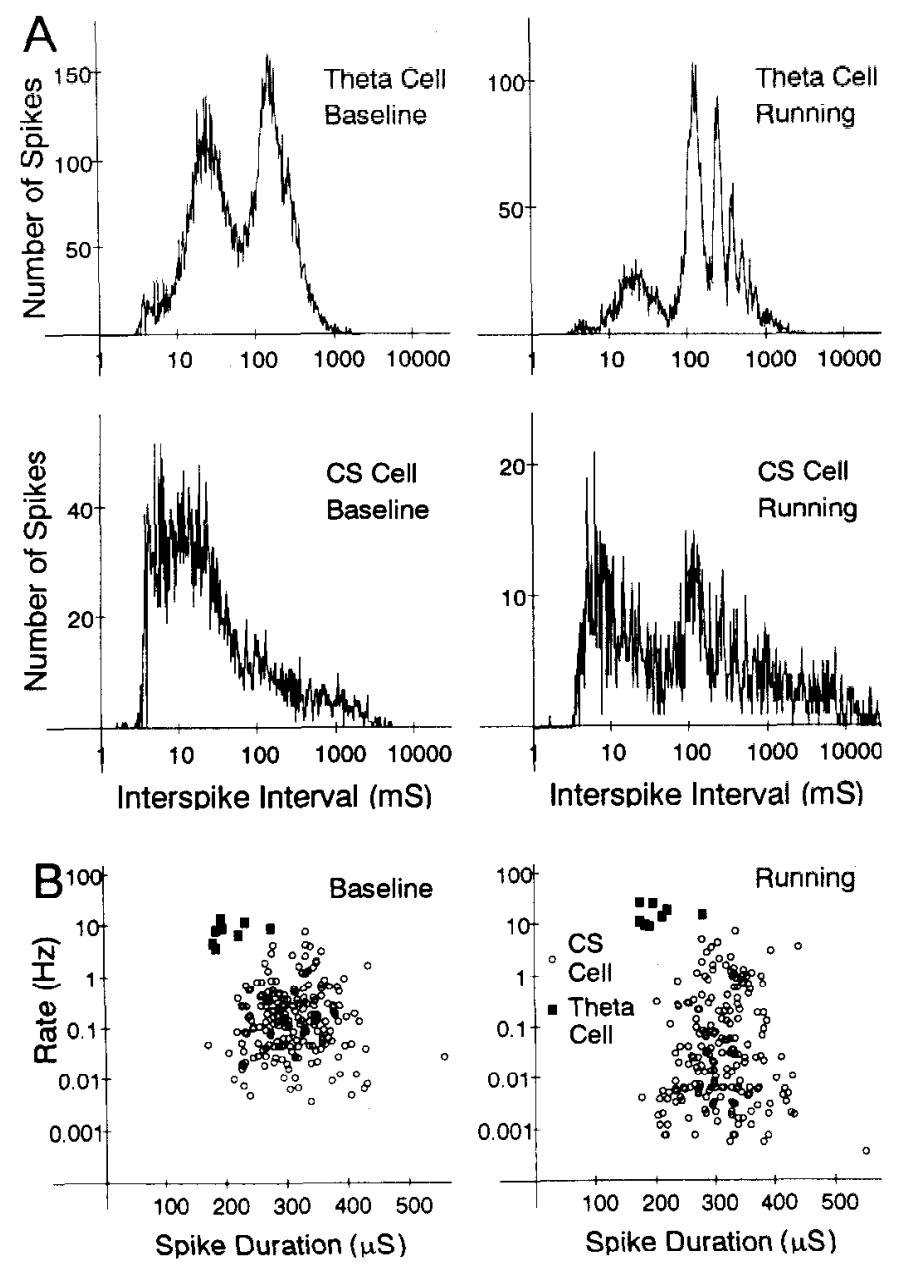

Figure 3. A, Interspike interval histograms during the baseline and the running periods are shown for typical complex spike and theta cells. Bursty units, classified as complex spike cells, exhibited multiple peaks around a $10 \mathrm{msec}$ interval (bottom left). Theta cells never showed this characteristic (top left). Instead, theta cell activities were strongly modulated at $7-8 \mathrm{~Hz}$ during the animal's active exploration in the recording apparatus (top right). B, Scatterplots of firing rate versus spike duration. Average unit firing rates during the baseline (left) and running (right) period were plotted against spike durations. In general, theta cells had short-duration spike waveforms and discharged at high rates, whereas complex spike cells had longer-duration waveforms and fired at low rates, as indicated by two clusters in the scatter plot. CS cell, complex spike cell.

cells seem similar to those of typical dorsal theta cells. Like dorsal theta cells, the ventral theta cells fired at high rates over all parts of the arena, although not homogeneously. Therefore, information per spike was low $(0.02 \pm 0.00$ bits for dorsal and $0.05 \pm 0.02$ bits for ventral) and the sparsity measure was high $(0.97 \pm 0.00$ for dorsal and $0.94 \pm 0.02$ for ventral) for both dorsal and ventral theta cells (Table 1). Information rate was $0.32 \pm 0.13$ and $0.50 \pm 0.17 \mathrm{bits} / \mathrm{sec}$ for dorsal and ventral theta cells, respectively. Spatial firing maps for all of the theta cells are shown in Figure 4.

\section{Discussion}

This study shows that CS cells and theta cells exist in the ventral hippocampus and that some ventral CS cells have spatially selective firing, as recently reported by a separate group (Poucet 

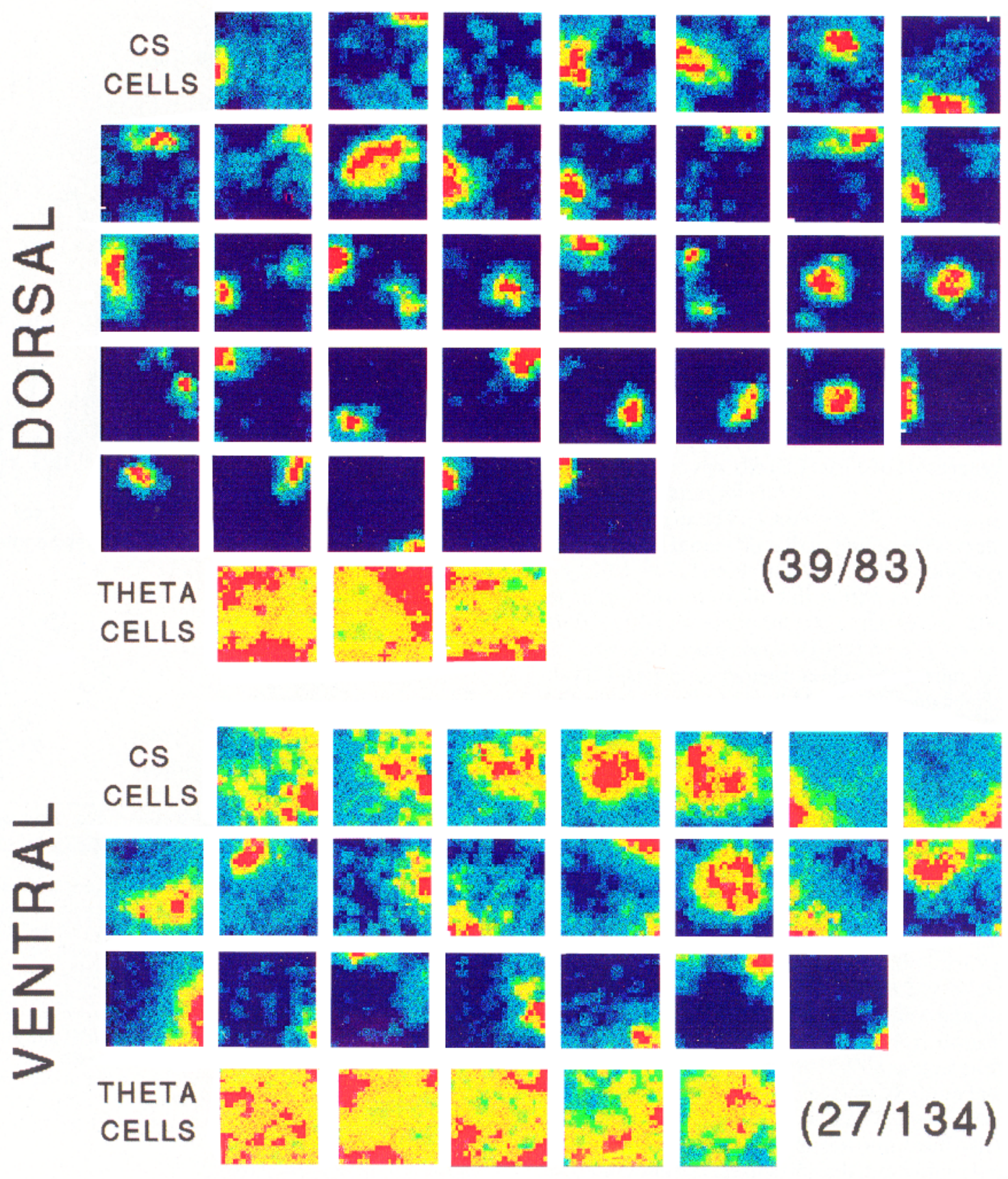

Figure 4. Spatial firing maps for place cells and theta cells. Spatial firing maps for all the dorsal and ventral place cells (complex spike cells with place fields; 36 of 80 for the dorsal and 22 of 129 for the ventral hippocampus) and theta cells are shown. Each panel represents the spatial distribution of the firing rate for one cell. Red indicates maximal firing rates, which are different for each cell, and dark blue indicates no firing. The last three of dorsal and the last five of ventral units are theta cells. For each cell type, cells are arranged depending on their information content measures in the ascending order (from left to right, top to bottom). Cells 1, 3, 5, 15, 16, 17, 18 and 21 of the dorsal place cells, and 15,18 and 21 of the ventral place cells had dual place fields. CS cells, complex spike cells.

et al., 1993); however, the proportion of ventral CS cells with place fields was markedly lower than that of the dorsal hippocampus. Furthermore, of those neurons that exhibited spatial selectivity, the resolution per cell was significantly lower in the ventral hippocampus, as shown by two different measures of spatial specificity. The average information rate was also lower for the ventral CS cells, indicating that more spatial information is conveyed by a given number of dorsal neurons than ventral neurons during a given time period.

The differences in spatial properties of dorsal and ventral hippocampal neurons may be associated with variations in the neuroanatomy and neurochemistry along the septotemporal axis. Differences in afferents received by the entorhinal cortex could, in turn, contribute to septotemporal differences in the hippocampal unit firing by virtue of topographic projections into the hippocampus. The parts of the lateral and the medial entorhinal cortices that receive direct projections from the perirhinal cortex, which appears to be a convergence site for neocortical sensory information (Van Hoesen and Pandya, 1975; Deacon et al., 1983; Room and Groenewegen, 1986a; Witter et al., 1986), 
project to the septal hippocampus. The parts of the lateral entorhinal cortex that have extensive amygdala inputs (Krettek and Price, 1977; Room and Groencwegen, 1986b; Insausti ct al., 1987) project to the temporal hippocampus in a topographic fashion (Ruth et al., 1982, 1988; Witter and Groenewegen, 1984; Witter et al., 1989b). Based on these anatomical features, it has been proposed that the septal hippocampus is more involved in the processing of sensory-related information whereas the temporal hippocampus is more involved in the processing of visceral-related information (Witter et al., 1986). One might suppose that the actual topography of inputs along the septotemporal axis in CA3 and the dentate gyrus would be substantially degraded within the CAl field if divergence of intrahippocampal projections is taken into account (Amaral and Witter, 1989). Our results, however, do show a septotemporal difference of spatial selectivity of CS cells and would suggest that those inputs required to distinguish spatial position in a small arena are likely to have a preferential projection nearer the septal pole of the hippocampus. This difference may be contributed in part by direct projections from the entorhinal cortex to area CA1, which show a similar longitudinal topographic organization as the perforant path-dentate gyrus projections (Wyss, 1981; Witter, 1993) and are perhaps less divergent (Tamamaki and Nojyo, 1992).

The gradients in topographic inputs to the hippocampus are accompanied by variations in neurotransmitter distributions. Septal cholinergic innervation is greater in the ventral hippocampus (Milner et al., 1983; Amaral and Kurz, 1985), and there exist septotemporal differences in binding affinities for muscarinic acetylcholine receptors (Garcia Ruiz et al., 1993). Dopaminergic innervation is almost completely limited to the ventral hippocampus (Verney et al., 1985). Concentrations of norepinephrine (Haring and Davis, 1985) and serotonin (Köhler et al., 1981) as well as the density of synaptic terminals containing these transmitters are higher in the ventral hippocampus (Gage and Thompson, 1980). Vasopressin-containing fibers are found only in the ventral hippocampus (Caffe et al., 1987), and enkephalin projections terminate only in the ventral parts of CA1 (Gall et al., 1981). Substance P (Mantyh et al., 1984), neuropeptide Y (Köhler et al., 1987), oxytocin (Van Leeuwen et al., 1985), and thyrotropin-releasing hormone (Pazos et al., 1985) receptors are preferentially found more ventrally. The general tendency appears to be that if a concentration gradient exists, whether for transmitters, neuromodulators, or receptors, it is denser toward the temporal pole of the hippocampus. Thus, the part of the hippocampus with less spatial selectivity is associated with a greater density of diverse neuroregulatory pathways. The greater number of neuromodulatory influences in the ventral hippocampus may have served as sources of uncontrolled variability and hence lower spatial resolution in our ventral hippocampal recordings.

Recent behavioral studies report that rats with dorsal hippocampal lesions were significantly more impaired in a Morris water maze task (Moser et al., 1993) and a spatial location order recognition task (Chiba et al., 1992) than rats with ventral hippocampal lesions. The lesions were made electrolytically, so there remains a possibility that the differential behavioral effects were due to damage to the fibers passing through dorsal hippocampus. Nevertheless, the results suggest that the dorsal hippocampus is more involved in processing of specific spatial information than the ventral hippocampus. The present results are consistent with this suggestion. Our data, however, do not
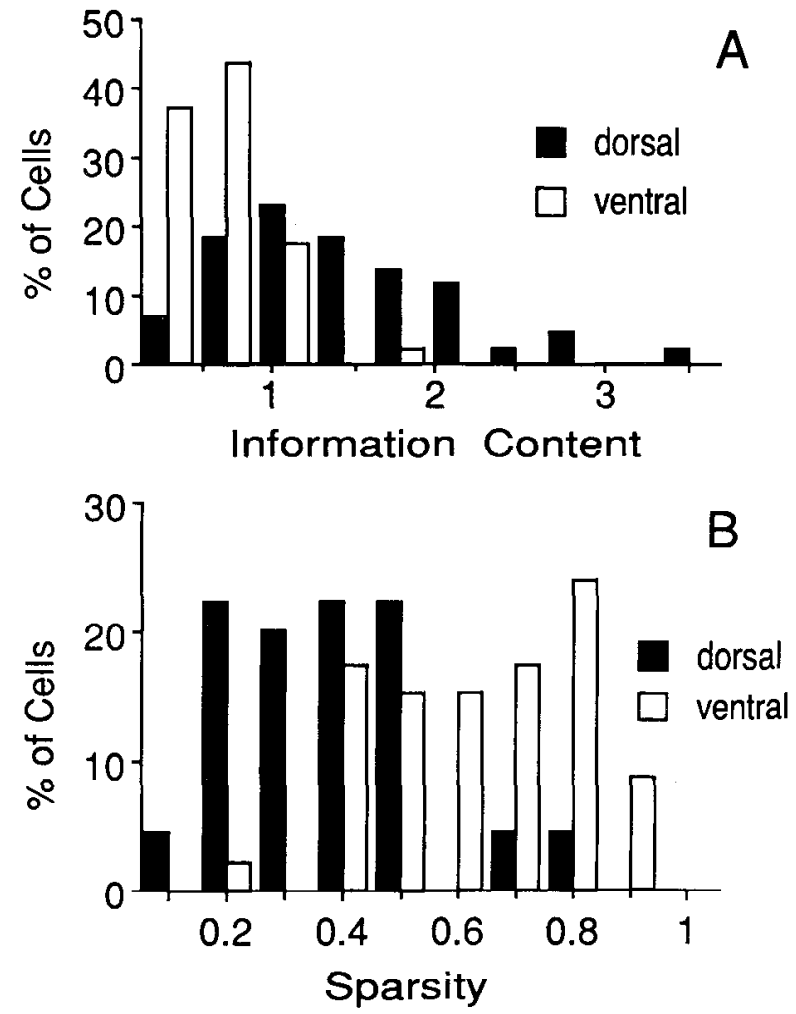

Figure 5. Distribution of sparsity and information content measur Most ventral complex spike cells were of lower information content ( and higher sparsity $(B)$ than dorsal complex spike cells. All cells tr fired 50 or more spikes during the behavior session are included (s Materials and Methods).

support the possibility that the ventral hippocampus is not $\mathrm{i}$ volved in processing of spatial information at all, since robi place cells were found in the present study as reported previous (Poucet et al., 1993). Rather, the present results suggest that $t$ modes of spatial information processing are different betwe the dorsal and the ventral hippocampus. As an example, $t$ dorsal hippocampus may deal with high-resolution spatial $i$ formation for a small environment (e.g., inside the arena) whe1 as the ventral hippocampus may process low-resolution infc mation for a large environment (e.g., the whole recording roon An intriguing but highly speculative possibility is that the exists a continuous gradient in the spatial resolution of $u$ firing along the septotemporal axis and that this gradient som how encodes spatial information (e.g., distance to a referen point). Another possibility is that the hippocampal represe tation of space permits episodic learning of associations 1 either small or large areas. It would seem to be inefficient employ many specialized, high-resolution place cells simul1 neously to code for information that concerns more than $h_{\text {i }}$ of the room.

Although there exists a statistically significant difference, $t$ overall firing rates of the dorsal and ventral CS cells in the are are within a close range $(0.29 \pm 0.05$ and $0.35 \pm 0.09 \mathrm{~F}$ respectively). This similarity reflects the fact that although the were fewer ventral cells active in the arena, their place fiel were larger. Thus, despite the differences in spatial tuning, $t$ overall fraction of cells active at any given moment is qu similar in the two areas. These findings are interesting in $\mathbf{t}$ context of neural network models of the hippocampus as 
associative memory system, which rely on sparse coding to attain high storage capacities (e.g., Marr, 1971; Tsodyks and Feigel'man, 1988; McNaughton and Nadel, 1990; Gibson and Robinson, 1992; Treves and Rolls, 1992; Minai and Levy, 1994). The principle of sparse coding is to represent each event to be stored with an activity pattern in which only a small fraction of the neurons are active. The size of this fraction (i.e., the "sparsity" of the representation) is a major factor influencing the storage capacity of the system. Our results are consistent with the possibility that activity patterns in the dorsal and ventral hippocampus are similar in terms of sparsity, even though the pattern in the dorsal region contains much more information about spatial location.

Numerous issues remain outstanding. For example, is there a continuous gradient in spatial selectivity along the entire septotemporal axis? Is there a computational advantage to encoding space simultaneously at different scales? Will the proportion of ventral place cells be maintained in larger environments, or ones with different charactcristics? How will ventral spatial firing patterns change in a task that explicitly demands spatial memory? What are the spatial correlates of unit discharges in the dentate gyrus and CA3 area of the ventral hippocampus? Are there other, possibly more salient behavioral correlates of ventral units; for example, are ventral units, which presumably receive more amygdala inputs, more tuned to the affective context of the lask or location? These questions require future investigation.

\section{References}

Amaral DG, Kurz J (1985) An analysis of the origins of the cholinergic and noncholinergic septal projections to the hippocampal formation of the rat. J Comp Neurol 240:37-59.

Amaral DG, Witter MP (1989) The three-dimensional organization of the hippocampal formation: a review of anatomical data. Neuroscience 31:571-591

Ashton D, Reempts J, Haseldonckx M, Willems R (1989) Dorsalventral gradient in vulnerability of CAl hippocampus to ischemia: a combined histological and electrophysiological study. Brain Res 487: 368-372.

Barnes CA, McNaughton BL, Mizumori SJY, Leonard BW, Lin L-H (1990) Comparison of spatial and temporal characteristics of neuronal activity in sequential stages of hippocampal processing. Prog Brain Res 83:287-300.

Blozovski D (1979) PA-learning in young rats with dorsal hippocampal- and hippocampo-entorhinal atropine. Pharmacol Biochem Behav 10:369-372.

Bragdon AC, Taylor DM, Wilson WA (1986) Potassium-induced epileptiform activity in area CA3 varies markedly along the septotemporal axis of the rat hippocampus. Brain Res 378:169-173.

Brazier MAB (1970) Regional activities within the human hippocampus and hippocampal gyrus. Exp Neurol 26:354-368.

Buzsáki G, Horvath Z, Urioste R, Hetke J, Wise K (1992) Highfrequency network oscillation in the hippocampus. Science 256:10251027.

Caffe AR, Van Leeuwen FW, Luiten PGM (1987) Vasopressin cells in the medial amygdala of the rat project to the lateral septum and ventral hippocampus. J Comp Neurol 261:237-252.

Cavazos JE, Golarai G, Sutula TP (1992) Septotemporal variation of the supragranular projection of the mossy fiber pathway in the dentate gyrus of normal and kindled rats. Ilippocampus 2:363-372.

Chiba AA, Johnson DL, Kesner RP (1992) The effect of lesions of the dorsal hippocampus or the ventral hippocampus on performance of a spatial location order recognition task. Soc Neurosci Abstr 18:1422.

Deacon TW, Eichenbaum H, Rosenberg P, Eckmann KW (1983) Afferent connections of the perirhinal cortex in the rat. J Comp Neurol 220:168-190.

Elul R (1964) Regional differences in the hippocampus of the cat. I.
Specific discharge patterns of the dorsal and ventral hippocampus and their role in generalized seizures. Electroencephalogr Clin Neurophysiol 16:470-488.

Ferino F, Thierry AM, Glowinski J (1987) Anatomical and electrophysiological evidence for a direct projection from Ammon's horn tc the medial prefrontal cortex. Exp Brain Res 65:421-426.

Fricke R, Cowan WM (1978) Autoradiographic study of the commissural and ipsilateral hippocampal-dentate projections in the adul1 rat. J Comp Neurol 181:253-270.

Gaarskjaer FB (1978) Organization of the mossy fiber system of the rat studied in extended hippocampi. I. Terminal area related to number of granule and pyramidal cells. J Comp Neurol 178:49-72.

Gage FH, Thompson RG (1980) Differential distribution of norepinephrine and serotonin along the dorso-ventral axis of the hippocam. pal formation. Brain Res Bull 5:771-773.

Gall C, Brecha N, Karten HJ, Chang K-J (1981) Localization of enkephalin-like immunoreactivity to identified axonal and neurona: populations of the rat hippocampus. J Comp Neurol 198:335-350.

Garcia Ruiz AJ, Zambelli M, La Porta C, Ladinski H, Consolo S (1993 Differences between rat dorsal and ventral hippocampus in musca. rinic receptor agonist binding and interaction with phospholipase $\mathrm{C}$ Eur J Pharmacol 244:125-131.

Gibson WG, Robinson J (1992) Statistical analysis of the dynamics of a sparse associative memory. Neural Networks 5:645-661.

Gilbert M, Racine RJ, Smith GK (1985) Epileptiform responses in ventral vs dorsal hippocampal slices. Brain Res 361:389-391.

Haring JH, Davis JN (1985) Differential distribution of locus coeruleus projections to the hippocampal formation: anatomical and biochemical evidence. Brain Res 325:366-369.

Insausti R, Amaral DG, Cowan WM (1987) The entorhinal cortex of the monkey: III. Subcortical afferents. J Comp Neurol 264:396-408.

Jay TM, Witter MP (1991) Distribution of hippocampal CA1 and subicular efferents in the prefrontal cortex of the rat studied by means of anterograde transport of Phaseolus vulgaris-leucoagglutin. J Comp Neurol 313:574-586.

Jay TM, Glowinski J, Thierry AM (1989) Selectivity of the hippocampal projection to the prelimbic area of the prefrontal cortex in the rat. Brain Res 505:337-340.

Jung MW, McNaughton BL (1993) Spatial selectivity of unit activity in the hippocampal granular layer. Hippocampus 3:165-182.

Knierim JJ, McNaughton BL, Duffield C, Bliss J (1993) On the binding of hippocampal place fields to the inertial orientation system. Soc Neurosci Abstr 19:795.

Köhler C, Chan-Palay V, Steinbusch H (1981) The distribution and orientation of serotonin fibers in the entorhinal and other retrohip. pocampal areas. An immunohistochemical study with anti-serotonir antibodies in the rat's brain. Anat Embryol (Berl) 161:237-264.

Köhler C, Schultzberg M, Radesäter A-C (1987) Distribution of neu. ropeptide $Y$ receptors in the rat hippocampal region. Neurosci Let1 75:141-146.

Koreli A (1977) Influences of dorsal and ventral hippocampus of hypothalamic self-stimulation. Physiol Behav 19:713-717.

Krettek JE, Price JL (1977) Projections from the amygdaloid complex and adjacent olfactory structures to the entorhinal cortex and to the subiculum in the rat and cat. J Comp Neurol 172:723-752.

Lanier LP, Isaacson RT (1975) Activity changes related to the location of lesions in the hippocampus. Behav Biol 13:59-69.

Laurberg S (1979) Commissural and intrinsic connections of the ra1 hippocampus. J Comp Neurol 184:685-708.

Lee PH, Xie CW, Lewis DV, Wilson WA, Mitchell CL, Hong JS (1990, Opioid-induced epileptiform bursting in hippocampal slices: highe susceptibility in ventral than dorsal hippocampus. J Pharmacol Exr Ther 253:545-551.

Li X-G, Somogyi P, Ylinen A, Buzsáki G (1994) The hippocampa CA3 network: an in vivo intracellular labeling study. J Comp Neuro 339:181-208.

Lopes Da Silva FH, Witter MP, Groenewegen HJ, Böeijinga PH, Loh. man AIIM (1990) Anatomic organization and physiology of the limbic cortex. Physiol Rev 70:453-511.

Mantyh PW, Maggio JE, Hunt SP (1984) Substance P receptors: lo. calization by light microscopic autoradiography in rat brain usin $\left[{ }^{3} \mathrm{H}\right] \mathrm{SP}$ as the radioligand. Brain Res 307:147-165.

Marr D (1971) Simple memory: a theory for archicortex. Philos Tran: $\mathrm{R}$ Soc Lond [Biol] 262:23-81.

McNaughton BL, Nadel L (1990) Hebb-Marr networks and the neu 
robiological representation of action in space. In: Neuroscience and connectionist theory (Gluck MA, Rumelhart D, eds), pp 1-63. Hillsdale, NY: Earlbaum.

McNaughton BL, Barnes CA, O'Keefe J (1983a) The contributions of position, direction and velocity to single unit activity in the hippocampus of freely moving rats. Exp Brain Res 52:41-49.

McNaughton BL, Barnes CA, O'Keefe J (1983b) The stereotrode: a new technique for simultaneous isolation of several single units in the central nervous system from multiple unit records. J Neurosci Methods 8:391-397.

McNaughton BL, Barnes CA, Meltzer J, Sutherland RJ (1989) Hippocampal granule cells are necessary for normal spatial learning but not for spatially-selective pyramidal cell discharge. Exp Brain Res 76: 485-496.

Milner TA, Loy R, Amaral DG (1983) An anatomical study of the development of the septo-hippocampal projection in the rat. Dev Brain Res 8:343-371.

Minai AA, Levy WB (1994) Setting the activity level in sparse random networks. Neural Comput 6:83-97.

Moser E, Moser M-B, Andersen P (1993) Spatial learning impairment parallels the magnitude of dorsal hippocampal lesions, but is hardly present following ventral lesions. J Neurosci 13:3916-3925.

Muller RU, Kubie JL, Ranck JB (1987) Spatial firing patterns of hippocampal complex-spike cells in a fixed environment. J Neurosci 7:1935-1950.

Nadel L (1968) Dorsal and ventral hippocampal lesions and bchavior. Physiol Behav 3:891-900.

O'Keefe J (1976) Place units in the hippocampus of the freely moving rat. Exp Neurol 51:78-109.

O'Keefe J, Dostrovsky J (1971) The hippocampus as a spatial map. Preliminary evidence from unit activity in the freely-moving rat. Brain Res 31:171-175.

O'Keefe J, Nadel L (1978) The hippocampus as a cognitive map. Oxford: Clarendon.

Olton DS, Branch M, Best PJ (1978) Spatial correlates of hippocampal unit activity. Exp Neurol 58:387-409.

Pazos A, Cortès R, Palacois JM (1985) Thyrotropin-releasing hormone receptor binding sites: autoradiographic distribution in the rat and guinea pig brain. J Neurochem 45:1448-1463.

Poucet B, Thinus-Blanc C, Muller RU (1993) A demonstration of place cells in the ventral hippocampus in rats. Soc Neurosci Abstr 19:796.

Racine R, Rose PA, Burnham WM (1977) Afterdischarge thresholds and kindling rates in dorsal and ventral hippocampus and dentate gyrus. Can J Neurol Sci 4:273-278.

Ranck JB (1973) Studies on single neurons in dorsal hippocampal formation and septum in unrestrained rats. Exp Neurol 41:461-555.

Recce M, O'Keefe J (1989) The tetrode: an improved technique for multi-unit extracellular recording. Soc Neurosci Abstr 15:1250.

Room P, Groenewegen HJ (1986a) Connections of the parahippocampal cortex. I. Cortical afferents. J Comp Neurol 251:415-450.

Room P, Groenewegen HJ (1986b) Connections of the parahippocampal cortex in the cat. II. Subcortical afferents. J Comp Neurol 251:451-473.

Russchen FT (1982) Amygdalopetal projections in the cat. I. Cortical afferent connections. A study with retrograde and anterograde tracing techniques. J Comp Neurol 206:159-179.

Ruth RET, Collier TJ, Routtenberg A (1982) Topography between the entorhinal cortex and the dentate septotemporal axis in rats. I. Medial and intermediate entorhinal projecting cells. J Comp Neurol 209:69-78.

Ruth RET, Collier TJ, Routtenberg A (1988) Topographical relationship between entorhinal cortex and the septotemporal axis of the dentate gyrus in rats: II. Cells projecting from lateral entorhinal subdivisions. J Comp Neurol 270:506-516.

Seress L, Pokorny J (1981) Structure of the granular layer of the rat dentate gyrus: a light microscopic and Golgi study. J Anat 133:181195.

Siegel A, Flynn HP (1968) Differential effects of electrical stimulation and lesions of the hippocampus and adjacent regions upon attack behavior in cats. Brain Res 7:252-267.

Siegel A, Tassoni JP (1971) Differential efferent projections from the ventral and dorsal hippocampus of the cat. Brain Behav Evol 4:185200.

Skaggs WE, McNaughton BL, Gothard KM, Markus EJ (1993) An information-theoretic approach to deciphering the hippocampal code. Adv Neural Inform Process Syst 5:1030-1037.

Stevens R, Cowey A (1973) Effects of dorsal and ventral hippocampal lesions on spontaneous alternation, learned alternation and probability learning in rats. Brain Res 52:203-224.

Swanson LW (1981) A direct projection from Ammon's horn to prefrontal cortex in the rat. Brain Res 217:150-154.

Swanson LW, Cowan WM (1977) An autoradiographic study of the organization of the efferent connections of the hippocampal formation in the rat. J Comp Neurol 172:49-84.

Swanson LW, Wyss JM, Cowan WM (1978) An autoradiographic study of the organization of intrahippocampal association pathways in the rat. J Comp Neurol 181:681-716.

Swanson LW, Köhler C, Björklund A (1987) The limbic region. 1: The septohippocampal system. In: Handbook of chemical neuroanatomy, Vol 5, Integrated systems of the CNS (Björklund A, Hokfelt T, Swanson LW, eds), pp 125-277. Amsterdam: Elsevier.

Tamamaki N, Nojyo Y (1992) Reciprocal connections between the subiculum, field CA1, the entorhinal cortex in the rat. Soc Neurosci Abstr 18:32.

Thompson LT, Best PJ (1989) Place cells and silent cells in the hippocampus of freely-behaving rats. J Neurosci 9:2382-2390.

Thompson LT, Best PJ (1990) Long-term stability of hippocampal place cell activity recorded from freely-behaving rats. Brain Res 509: 299-308.

Tsodyks MV, Fcigcl'man MV (1988) The enhanced storage capacity of neural networks with low activity level. Europhys Lett 6:101-105.

Treves A, Rolls ET (1992) Computational constraints suggest the need for two distinct input systems to the hippocampal CA3 network. Hippocampus 2:189-200.

Van Groen T, Lopes Da Silva FH (1985) Septotemporal distribution of entorhinal projections to the hippocampus in the cat: electrophysiological evidence. J Comp Neurol 238:1-9.

Van Groen T, Lopes Da Silva FH (1986) Organization of the reciprocal connections between the subiculum and the entorhinal cortex in the cat. II. An electrophysiological study. J Comp Neurol 251:111-120.

Van Groen T, Wyss JM (1990) Extrinsic projections from area CA1 of the rat hippocampus: olfactory, cortical, subcortical, and bilateral hippocampal formation projections. J Comp Neurol 302:515-528.

Van Groen T, Van Haren FJ, Witter MP, Groenewegen HJ (1986) The organization of the reciprocal connections between the subiculum and the entorhinal cortex in the cat. I. A neuroanatomical tracing study. J Comp Neurol 250:485-497.

Van Hoesen GW, Pandya DN (1975) Some connections of the entorhinal (area 28) and perirhinal (area 33) cortices of the rhesus monkey. I. Temporal lobe afferents. Brain Res 95:1-24.

Van Leeuwen F, Van Heerikhuize J, Van der Meulen G, Wolters P (1985) Light microscopic autoradiographic localization of $\left[{ }^{3} \mathrm{H}\right]$ oxytocin binding sites in the rat brain, pituitary and mammary gland. Brain Res 359:320-325.

Verney C, Baulac M, Berger B, Alvarez C, Vigny A, Helle KB (1985) Morphological evidence for a dopaminergic terminal field in the hippocampal formation of young and adult rat. Neuroscience 14:10391052.

Williamson JM, Bertram EH, Lothman EW (1991) Rapid kindling indicates regional differences in epileptogenicity in the hippocampal formation. Epilepsia 32[Suppl 3]:40.

Wilson MA, McNaughton BL (1993) Dynamics of the hippocampal enscmblc code for spacc. Scicncc 261:1055-1058.

Witter MP (1986) A survey of the anatomy of the hippocampal formation, with emphasis on the septotemporal organization of its intrinsic and extrinsic connections. In: Advances in experimental medical biology, Vol 203, Excitatory amino acids and epilepsy (Schwarcz R, Ben-Ari Y, eds), pp 67-82. New York: Plenum.

Witter MP (1993) Organization of the entorhinal hippocampal system - a review of current anatomical data. Hippocampus 3:33-44.

Witter MP, Groenewegen HJ (1984) Laminar origin and septotemporal distribution of entorhinal and perirhinal projections to the hippocampus in the cat. J Comp Neurol 224:371-385.

Witter MP, Room P, Groenewegen HJ, Lohman AHM (1986) Connections of the parahippocampal cortex: V. Intrinsic connections: comments on input/output connections with the hippocampus. J Comp Neurol 251:451-473.

Witter MP, Holtrop R, van de Loosdrecht AA (1988) Direct projec- 
tions from the periallocortical subicular complex to the fascia dentata in the rat. Neurosci Res Commun 2:61-68.

Witter MP, Groenewegen HJ, Lopes Da Silva FH, Lohman AHM (1989a) Functional organization of the extrinsic and intrinsic circuitry of the parahippocampal region. Prog Neurobiol 33:161-253.

Witter MP, Van Hoesen GW, Amaral DG (1989b) Topographical organization of the entorhinal projection to the dentate gyrus of the monkey. J Neurosci 9:216-218.
Wyss JM (1981) An autoradiographic study of the efferent connections of the entorhinal cortex in the rat. J Comp Neurol 199:495-512.

Wyss JM, Van Groen T (1992) Connections between the retrosplenial cortex and the hippocampal formation in the rat: a review. Hippocampus $2: 1-12$. 